\title{
Easy Bleeding
}

National Cancer Institute

\section{Source}

National Cancer Institute. Easy Bleeding. NCI Thesaurus. Code C95552.

Bleeding that is disproportionate to the offending trauma. 